\title{
O REFLEXO DE DISTRITOS INDUSTRIAIS EM PEQUENOS MUNICIPIOS DE GOIÁS
}

\author{
MARIO CESAR GOMES DE CASTRO
}

Universidade Estadual de Goiás (UEG) / Universidade de Brasília (UnB)

\begin{abstract}
RESUMO
Varios são os instrumentos empregados pelo governo do Estado de Goiás para promover a industrialização, dos quais se destacam o incentivo fiscal e os terrenos com infraestrutura. Estes últimos, chamados de Distritos Industriais, aqui objeto de pesquisa, foram instalados em trinta cidades do Estado pelo governo, com a finalidade de atrair empresas e as tornar polos de desenvolvimento. Este enfoque motivou o objetivo desta pesquisa que foi o de conhecer os reflexos destes distritos em pequenos municípios do Estado. O foco recaiu sobre a realidade de Abadiânia e Orizona. Para tanto, foi elaborado um estudo descritivo, complementado com aplicação de questionário às empresas instaladas nos Distritos Industriais para se constatar o reflexo destas empresas nas economias locais. O resultado de vários anos de existência destes distritos nestes municípios foi que dos resultados esperados, a criação de polos de crescimento não se concretizou, pois há pouco envolvimento com a economia local, restringindo-se basicamente à oferta de empregos.
\end{abstract}

Palavras-chave: Política Pública. Política Industrial. Distritos Industriais. Abadiânia. Orizona.

\section{SUMMARY}

Various are the instruments employed by the state of Goias government to promote industrialization, among which are the tax incentives and land with infrastructure. The latter, called Industrial Districts, here object of research, were installed in thirty cities in the state by the government, in order to attract businesses and become development poles. This approach led to the objective of this research was to know the consequences of these districts in small municipalities. The focus was on the reality of Abadiania and Orizona. Thus, a descriptive study was conducted, supplemented with a questionnaire to the companies located in the Industrial Districts to observe the reflection of these companies on local economies. The result of several years of existence of these districts in these municipalities was that the expected results, the creation of poles of growth did not materialize because there is little involvement with the local economy and restricted mainly to the supply of jobs.

Keywords: Public Policy. Industrial Policy. Industrial Districts. Abadiania. Orizona.

Área ABEIN / classificação JEL do trabalho: L38 Public Policy 


\section{INTRODUÇÃO}

A política industrial em Goiás é empregada como instrumento para equilibrar as condições concorrenciais deste para com outros estados que já vem estimulando suas economias desde a introdução do regime republicano no Brasil. Evidencias de tal fato se encontra na Constituição de 1935, quanto nesta há referencias à isenção fiscal para empresas industriais e comerciais que viessem a se instalar em Goiás, portanto, a mais de 80 anos os governantes buscam meios de tornar o Estado interessante para o capital privado.

Incialmente o instrumento foi o incentivo fiscal, através da isenção fiscal. Com o passar do tempo houve ampliação da politica com a facilitação de crédito, surgimento de órgãos administrativos para coordenar as ações de estimulo à industrialização, incentivo à inovação e criação de infraestrutura, principalmente via implantação de Unidade de Desenvolvimento Industrial - ou Distritos Industriais.

As principais ações foram criadas a partir dos anos de 1958 e fortalecidas na Decada de 1980, momento em que o Governo Federal se distanciou das políticas de desenvolvimento regional no Brasil. Periodo também em que se evidenciam os reflexos da descentralização industrial, iniciada na década de 1970, na Região Sudeste (SABOIA, 2000; CANO, 2008).

O reflexo de tais fatos pode ser observado pela variação da participação do setor industrial no Produto Interno Bruto (PIB) do Estado, quando se teve elevação de 7,9\% em 1960 para 17,9\% em 1970, mantendo-se em crescimento até o ano 2000, quando chegou a 32,5\% e se tem 26,6\% em 2010 (GOIÁS. 1999; 2000; 2002 e 2012).

Esta ampliação da industrialização, contudo, foi concentradora de indústrias, de riquezas e pessoas nas maiores cidades do Estado, bem como, de recursos destinados pelo governo estadual para estas mesmas cidades.

Dos instrumentos empregados citados acima, a criação de espaços ou distritos industriais foi destaque para a atração de empresas. Foram implantados em cidades de grande e pequeno porte, consideradas polo para o crescimento do Estado. Contudo, o resultado esperado, a promoção do desenvolvimento não atingiu a todas as comunidades como se esperava.

Os resultados da interação entre as empresas dos Distritos Industriais (DIs) criados pelo governo do Estado com os pequenos municípios não são conhecidos. Daí o interesse desta pesquisa em estudar as áreas destinadas à instalação de empresas industriais - os Distritos Industriais, em pequenos municípios, com o objetivo de se conhecer a efetividade destes espaços em promover o desenvolvimento local. Para tanto, teve-se como objeto de pesquisa os Distritos de Abadiânia e Orizona.

As seguir vai-se tratar de alguns conceitos de política industrial e de seus instrumentos para se ententer os resultados encontrados.

\section{POLITICA INDÚSTRIA, CONCEITOS E INSTRUMENTOS: DESTAQUE PARA O DISTRITO INDUSTRIAL}

A politica industrial que vem a ser, "a criação, a implementação, a coordenação e o controle estratégico de instrumentos destinados a ampliar a capacidade produtiva e comercial da indústria, a fim de garantir condições concorrenciais sustentáveis nos mercados internos e externo” (FLEURY; FLEURY, 2004. p. 14), é uma parte da Política Pública que pode ser “entendida como ações, práticas, diretrizes políticas, fundadas em leis e empreendidas como funções de Estado por um governo, para resolver questões gerais e especificas da sociedade” (HEIDEMANN; SALM, 2009, p. 29).

As visões existentes sobre a Política Industrial podem ser agrupadas em diferentes abordagens teóricas, que segundo Castro (2002) e Ferraz et al. (2002), são em três tipos representativos dentro do controverso universo do pensamento econômico, sendo elas: a) a ortodoxa que vê a política industrial como necessária, somente quanto há 'falhas de mercado'; b) a desenvolvimentista, que vê a participação 
do Estado na gestão da política industrial como legitima, para a promoção do desenvolvimento; e por fim, c) a evolucionista, que vê na inovação a criação efetiva da competitividade.

Por ser uma ação que lato sensu, subentende a intervenção do estado, como prática inclusive nos países mais liberais, é convergente para a aceitação que a Politica Industrial (FERRAZ et al., 2002) seja entendida como um conjunto de incentivos e regulações associadas a ações públicas que afetam a alocação de recursos, influenciando a estrutura produtiva e patrimonial, no que concordam Fleury et al. (2004), quando acrescentam que isso garante condições concorrenciais sustentáveis aos mercados internos e externo.

A aplicação dos instrumentos da Política Industrial pode ser feita, como sugere Chang (1994), diretamente a empresas específicas - política vertical; ou políticas que abrangem o crescimento da economia como todo - as políticas horizontais. Para tanto, segundo Ferraz et al. (2002), tem-se como exemplo:

- para políticas verticais, ações que tenham como beneficiária a empresa ou setor: a) com maior valor agregado; b) com grande poder de encadeamento; c) com grande dinamismo potencial; d) as empresas nascentes;

- no caso de políticas horizontais: a) de ações para controle de monopólios e oligopólios; b) infraestruturas; c) regulação do comércio externo; d) incentivo à inovação; e) incentivos fiscais; entre outros.

Dentro das infraestruturas se encaixa o Distrito Industrial, como uma ação de intervenção do estado em dado território como instrumento no campo da politica pública para atração de indústrias. Por outro lado, a concepção das áreas destinadas à instalação de indústrias em Goiás e no Brasil, denominados de Distritos Industriais se fundamenta na capacidade de impactarem o território em que estão inseridos, como discutem Marshall, Perroux, Myrdal e Hirschman, autores que estudaram as consequências do agrupamento de pessoas e os fatores que levam empresas e pessoas a concentrarem em determinados locais, ou que forças ou elementos justificam o agrupamento produtivo.

O principio da discussão sobre distritos ou aglomerações na economia é atribuída à explicação do movimento de concentração produtiva na obra de Marshall (1996) intitulada "Princípio de Economia”, quando o autor apresenta como norteadores para a decisão de localizar os seguintes fatores externos $^{1}$ (externalidades marshallianas):

a) as condições físicas (clima, solo, minas e pedreiras), no caso de indústrias metalúrgicas, das cerâmicas, das indústrias de trançados de palha, da cutelaria, entre outras empresas que necessitavam ficar próximas da fonte de matéria-prima;

b) o patrocínio do Estado, que reúne grande e exigente demanda por produtos e serviços de alta qualidade, o que provoca deslocamento de muitos trabalhadores especializados que, a seu turno, irão transferir conhecimentos para os trabalhadores locais;

c) a proximidade das fábricas que favorece a disseminação do conhecimento e agrupamento de operários com maiores habilidades onde os segredos da profissão passam a ser dissiminados, e, por assim dizer, ficam soltos no ar para qualquer pessoa se apossar deles;

d) custo do frete menor (ou tarifa alfandegária);

e) ganhos de produtividade, pela produção em larga escala (MARSHALL, 1996).

Outra visão importante que trata dos aspectos da concentração industrial é a de Perroux (1967, p. 151), ao dizer que:

a empresa ocupa um espaço definido como campo de forças. Como campo de forças, o espaço econômico é constituído por centros (polos ou sedes) de emanação de forças centrífugas e recepção de forças centrípetas. Cada centro, que é ao mesmo tempo centro de atração e de repulsa, tem o seu próprio campo, que é invadido pelos campos de outros

\footnotetext{
${ }^{1}$ Podem-se dividir as economias derivadas de um aumento da escala de produção de qualquer espécie de bens em duas classes: primeira, as dependentes do desenvolvimento geral da indústria; e segunda, as dependentes dos recursos das empresas que a ela se dedicam individualmente, das suas organizações e eficiência de suas administrações. Podem-se chamar as primeiras de economias externas, e as últimas de economias internas (MARSHALL, 1996, p.315).
} 
centros. Sob este aspecto, um espaço vulgar qualquer é receptáculo de centros e ponto de passagem de forças.

Considera-se como centro a empresa que libera: a) forças centrífugas, que afastam atividades turísticas, terrenos reservados para expansão posterior da atividade; e, b) forças centrípetas, que atrai ao espaço vulgar homens e coisas - concentra em torno da empresa, materiais e pessoas. Portanto, a localização da atividade industrial atrai os elementos econômicos, ofertas e procuras, ao seu espaço de plano, ou afasta-os dele.

Para Perroux (1967), o crescimento não surge em toda parte ao mesmo tempo, mas se manifesta com intensidades variáveis em pontos ou polos de crescimento e a consequência é a propagação por vias diferentes e com efeitos variáveis no resto da economia. O começo de tais polos acontece por empresas que o autor denomina de indústria motriz ${ }^{2}$, que depois de instalada, ao redor de si vai atraindo vendedores, mão de obra, entre outros elementos, que se relacionam com a atividade industrial, provocando forte expansão e crescimento.

O autor acrescenta, ainda, que a intensificação da atividade produtiva causa efeitos de disparidades inter-regionais, pois a concentração provoca transformações no meio geográfico imediato e, dependendo da força dessa concentração produtiva, poderá transformar a economia nacional. Perroux (1967, p. 175) comenta também que:

Centro de acumulação e concentração de meios humanos e de capitais fixos e fixados, chama à existência outros centros de acumulação e concentração de meio humanos e de capitais fixos e fixados. Quando dois destes centros entram em comunicação graças a vias de transporte material e intelectual, extensas transformações e desenham no horizonte econômico e nos planos de produtores e consumidores.

Portanto, nesta concepção, a inter-relação entre áreas que se destacam (indústrias motrizes, polos de indústrias e de atividade geograficamente concentradas) e áreas de menor atividade produtiva (indústrias movidas, regiões dependentes dos polos geograficamente concentrados), quando os primeiros estimulam estes outros, propiciará o crescimento local e que dada às circunstâncias poderá ter crescimento nacional.

Um importante reforço às ideias sobre as causas da concentração de empresas é o estudo dos efeitos da causação circular e acumulativa de Myrdal (1972) quando explica que uma ação ou fato ocorrido em determinada economia (ou local) irá desencadear reações que podem ser negativas ou positivas. Cita, ainda, como exemplo, que a saída de uma indústria de um dado local irá provocar desemprego e, como consequência, cairá a renda e a demanda e redundará em redução do emprego em outros setores (negócios) da comunidade. O contrário poderá ocorrer como fato positivo, ou seja, uma decisão de implantar uma indústria em determinado local promoverá o desenvolvimento geral.

Neste ponto, pode-se destacar que, ocorrido um fato que promova a desigualdade entre regiões e que os efeitos (da implantação de uma indústria, por exemplo) são acumulativos em favor do local, gera-se a preocupação com o restabelecimento de um equilíbrio, ou de reversão da desigualdade que não será automática, como ditam os liberais, pois as forças de mercado não estão preocupadas em promover a igualdade entre as regiões e na sociedade, pelo contrário, as forças de mercado, segundo o autor, tendem a aumentar e não a diminuir as desigualdades regionais. Para contornar tais fatos Myrdal (1972, p. 51) afirma que,

\footnotetext{
${ }^{2}$ Perroux (1967) define como indústria motriz a indústria que tem capacidade de aumentar suas vendas, aumentar de outra ou de várias outras, a indústria que foi afetada pela venda da primeira ele a denomina de indústria movida. Chama de indústria chave a que induz na totalidade de um conjunto, por exemplo, de uma economia nacional, um acréscimo global de vendas muito maior que o acréscimo de suas próprias vendas. "Quer dizer que não se pode organizar, de uma vez por todas, uma lista de indústrias-chaves, de acordo com suas características exteriores e técnicas. As indústrias que fabricam complementares múltiplos (matéria-prima, energia, transporte) tendem, sem dúvidas, a tornar-se indústrias-chaves, mas para que se revistam desse caráter, devem satisfazer outras condições” (PERROUX, 1967. p. 152). Segundo ainda o autor, a definição de indústriaschaves é relativa, e será atribuída segundo o conjunto de indústrias movidas e do período.
} 
se as forças do mercado não fossem controladas por uma política intervencionista, a produção industrial, o comércio, os bancos, os seguros, a navegação e de fato, quase todas as atividades econômicas que, na economia em desenvolvimento, tendem a proporcionar remuneração bem maior do que a média, e, além disso, outras atividades como a ciência, a arte, a literatura, a educação e a cultura superior se concentrariam em determinadas localidades e regiões deixando o resto do país de certo modo estagnado.

Dentre os vários fatores enumerados por Myrdal como resultantes das forças de causação circular que levam à concentração, pode-se destacar: a) migração, movimento de capital e comércio, que se expande em um local e produz 'efeito regressivo' em outros; b) fatores ‘não econômicos', que não são em geral considerados pela teoria econômica, mas que, por operarem por meio de cadeias causais e acumulativas, tendem à desigualdade regional, como a construção de serviços públicos para atender a região em desenvolvimento e certo descaso com as regiões menos favorecidas, aumentando as desigualdades (como estradas de ferro, programas de assistência médica, escolas).

Em contrapartida, existem os 'efeitos propulsores', ou 'centrífugos', que se propagam dos centros dinâmicos da economia para outras regiões. As regiões que se localizam em torno do centro dinâmico tendem a beneficiar-se pelo mercado crescente, estimulado pelo progresso técnico seja pelo fornecimento de matérias-primas, da produção de bens de consumo, produtos agrícolas ou mesmo por intermédio de demandas ampliadas. Nesse sentido, afirma-se que à medida que esses movimentos de crescimento industriais dispersos aumentam, elevam com eles o padrão econômico do país, reforçando as colocações de Perroux.

O outro importante pensador da aglomeração e seus efeitos é Hirschman (1961), para o qual o desenvolvimento é mais uma consequência de provocação e mobilização de recursos, fatores de produção e aptidões, do que de uma ótima confluência destes, que se encontram ocultos, dispersos ou mal empregados. Uma vez provocada a implantação da indústria, ela mesma irá proporcionar alterações através da influência na oferta e demanda na região beneficiada.

Para a promoção do desenvolvimento, é necessária uma visão 'mais audaciosa' em regiões mais atrasadas de um país em desenvolvimento, pois (idem, p. 278) “o que parece acontecer é que as economias externas, devidas aos polos, embora reais, são asseguradamente superestimadas pelos operadores econômicos”. As consequências podem ser: a) depreciação da renda da região menos favorecida (sul); e, b) forte migração de mão de obra, com destaque para os mais qualificados em busca de melhores remunerações. Neste caso, aparece a importância do papel dos governos para reduzir tais disparidades.

Complementando a discussão anterior que tem caráter mais tradicional ao discutir a aglomeração, destaca-se o trabalho de Storper cuja obra apresenta maior abrangência e profundidade dos motivos que levam à decisão da localização. Em seus textos, ele chama a atenção para o fato de que além do rendimento crescente, a participação dos agentes locais é fundamental para a organização dos fatores do processo acumulativo.

O posicionamento de Storper (1997) defende que seja chamada de ativos relacionais, de interdependência não comercializável a participação dos agentes, da cultura, da identidade do território, do conjunto dos recursos existentes nas redes, que são consequência de laços, conexões e relacionamentos, que vão além das externalidades pecuniárias da visão microeconômica.

E segundo Fujita e Krugman (2004) o desenvolvimento pode ser mais uma consequência de provocação e mobilização de recursos, fatores de produção e aptidões, do que de uma ótima confluência destes. E que os acidentes históricos continuam tendo uma importância capital.

O DI como concebido em Goiás atende aos preceitos teóricos e de ser agente propussor do desenvolvimento do local onde existem, pois atualmente ele representa "uma entidade socioterritorial caracterizada pela presença ativa de uma comunidade de pessoas e de uma população de empresas num determinado espaço geográfico" (BECATTINI, 2004). É um “tecido de relações horizontais onde se processa a aprendizagem coletiva e o desenvolvimento de novos conhecimentos através da combinação entre concorrência e cooperação" (FERREIRA, 2003). 


\section{OS DISTRITOS INDUSTRIAIS EM GOIÁS}

A criação das Unidades de Desenvolvimento Industrial (UDIs) - tais como: Condomínios, Polos, Distritos, Áreas Industriais e Integrados de Produção (GOIÁS, 1973a), amplamente divulgadas nos documentos oficiais como 'distritos industriais', deu-se para serem empregadas como instrumento de política industrial pelo governo do estado. Tal evento advem do movimento industrizalizante que deu passos a mais além dos benefícios fiscais, com a criação de infraestrutura na busca de aumentar a atratividade do estado para investimentos industriais. O objetivo da criação dos distritos, segundo a exposição de motivos para a criação da Lei n. 7.766/73 (GOIÁS, 1973a), era a de "processar a matériaprima oriunda da agricultura e da pecuária”.

Para gerir os distritos industriais criados, surgiu a Companhia dos Distritos Industriais de Goiás - a GoiasIndustrial ${ }^{3}$, pela Lei no 7.766/73 (GOIÁS, 1973a), instituição responsável por expandir as atividades agroindustriais do estado, através do estudo das potencialidades econômicas e sociais regionais para a escolha das cidades a sediarem os primeiros distritos goianos. Estudo que culminou na decisão de criar o primeiro distrito industrial no município de Anápolis, por este agregar as melhores condições históricas, econômicas, urbanas e sociais almejadas (CUNHA, 2010).

A Goiasindustrial conta com 33 distritos industriais, quase 400 empresas distribuídas em 30 municípios em todas as regiões do estado de Goiás (GOIASINDUSTRIAL, 2014). Os benefícios a serem concedidos aos empreendimentos que se instalam nesses distritos vão desde a disponibilização de espaços adequados, com localização planejada e infraestrutura básica com a garantia de fornecimento de água e esgoto, a possibilidade de integração com empresas regionais e do mesmo setor para a troca de experiências e aplicação de novas técnicas e os incentivos fiscais estaduais próprios para essas regiões (GOIASINDUSTRIAL, 2014).

O distrito pioneiro, com posição destacada no estado é o DAIA - Distrito Agroindustrial de Anápolis . Instalado em 09 de novembro de 1976 em uma área de 880 há, o DAIA possui uma infraestrutura completa com "pavimentação asfáltica, sistema de água e esgoto, rede de energia elétrica, sede administrativa, estação de tratamento de água e efluentes, plano de gestão ambiental, posto policial, urbanização, condomínio tecnológico, entre outros benefícios” (GOIÁS, 2007). Situação diferente dos que são objeto desta pesquisa, conforme será visto adiante.

Os dados disponíveis sobre os distritos industriais goianos estão concentrados no sitio do Goiasindustrial/Codego e do Instituto Mauro Borges. Estes dados são limitados, pois apresentam algumas características da infraestrutura, distância da capital e número de empresas, fato que dificulta análises mais profundas. Há também estudos acadêmicos que tratam da temática, contudo, restringem-se aos grandes municípios, sendo o DAIA (Anápolis), o grande destaque, como pode ser visto em Silva (2000), Castro (2004), Ribeiro (2008), Barreto (2009), Cunha (2010), Silva e Mendonça (2010) e Lauria; Moisés e Pasqualetto (2012).

\section{SOBRE A PESQUISA REALIZADA}

Deste contexto de emprego dos Distritos Industriais como instrumento de política industrial pelo governo do Estado, é que se surgiu o objetivo de se conhecer os impactos oriundos da implantação dos Distritos Industriais na estrutura produtiva de pequenos municípios, no cerne das teorias de desenvolvimento regional, à luz dos autores clássicos, Hirschman, Perroux e Myrdal.

Para atingir o objetivo citado, realizou-se estudo descritivo (GIL, 2010; RAMPAZZO, 2010) com a intenção de comparar e/ou cruzar variáveis ligadas aos objetivos da política que criou os DIs em

\footnotetext{
${ }^{3}$ A GoiásIndustrial foi substituída em 2015 pela Companhia de Desenvolvimento de Goiás (CODEGO), instituída pela Lei n. 19.064 de 14/10/2015, que mantem as mesmas funções.
} 
Goiás, com o grau envolvimento das industriais instaladas com o local e a região. Os objetos de pesquisa foram os DIs de Abadiânia e Orizona. Municipios com população inferior a 15.000 habitantes em 2010.

A pesquisa foi dividida em duas partes. Na primeira fez-se levantamento bibliográfico, na segunda parte se efetivou a pesquisa de campo, que foi subdivida em um primeiro momento na visita aos DIs escolhidos para um levantamento in loco do universo de empresas instaladas nos DIs, pois as informações existentes sobre o número de empresas são inconsistentes. Os dados do órgão responsável (Goiásindustrial/Codese) não são iguais ao que consta nos registros das prefeituras e ambos são diferentes do número existente fisicamente nos DIs, e no segundo momento, teve-se a aplicação de questionários ao total de empresas encontradas como universo. O emprego de tal instrumento se mostrou suficiente para se entender o envolvimento das empresas com a economia local, objetivo desta pesquisa, para tanto, não se fez entrevistas com os responsáveis pelas empresas.

O Distrito Agroindustrial de Abadiânia conta com quatro indústrias sendo que duas estão desativadas e em Orizona, estão instaladas doze empresas, com dez em funcionamento regular. Das empresas destes dois municípios se obteve respostas de nove. Não serão detalhados os dados das empresas respondentes por municípios, por questão da confidencialidade dos dados, fato garantido aos respondentes do questionário apresentado o que não prejudica a análise dos dados.

\section{CARACTERIZAÇÃO DOS MUNICIPIOS PESQUISADOS - Abadiânia e Orizona}

\section{a) Histórico dos Munícipios}

\section{- Abadiânia - Goiás}

O povoamento do município de Abadiânia se deu com a ocupação das terras às margens do Rio Capivari no Município de Corumbá de Goiás, em 1874, terras de boa qualidade para plantio de diversas culturas. Em 1943 o povoado se transformou em Distrito e se tornou município me 1953.

Com a criação da BR 153, a sede do município que ficava (atual distrito de Posse da Abadia) próximo da rodovia que liga a atual sede à Pirenopolis, foi transferida para as margens daquela rodovia em 1963.

A área do município é de 1.044.159 km², o que representa 0,31\% do Estado. A altitude média de Abadiânia é de 1.052m. Seus limites fronteiriços são: Alexânia, Anápolis, Corumbá de Goiás, Gameleira de Goiás, Pirenópolis e Silvânia. E esta a $85 \mathrm{~km}$ da capital do Estado, e se localiza na microrregião do Entorno de Brasília e na Mesorregião do Leste Goiano.

O Distrito Agroindustrial de Abadiânia (DAIAB) tem área de 22,74 ha, com a seguinte infraestrutura: EIA/RIMA aprovado, pavimentação asfáltica, registrado em cartório, rede de distribuição elétrica (GOIASINDUSTRIAL, 2014).

\section{Orizona - Goiás}

A ocupação das terras que atualmente formam o município teve inicio nas margens do Ribeirão Santa Bárbara em 1850. Em 1890 se transformou em distrito do Município de Santa Cruz e foi elevado à categoria de município em 1909.

Altitude é de $806 \mathrm{~m}$. com área de 1.972,865 km², correspondendo à 0,58\% do território do Estado de Goiás. E tem como limite os muncipios de Ipameri, Luziânia, Pires do Rio, Urutaí, Vianópolis e Silvânia, e está localizado na Microrregião de Pires do Rio e na Mesorregião do Sul Goiano. Esta a 129 km da capital do Estado.

O Distrito Agroindustrial de Orizona (DAIO) é o que apresenta menor infraestrutura a disposição das empresas, tendo, Pavimentação asfáltica, EIA/RIMA - licença ambiental (GOIASINDUSTRIAL, 2014). Neste município há também um distrito industrial criado pela prefeitura municipal. 


\section{b) Análise comparativa dos municípios - dados diversos.}

\section{b.1 A população}

Em Abadiânia a população em 2010 era 15.757, apresentava em relação à média estadual baixo nível de urbanização somente 68,4\%. Contudo, tem elevada taxa de crescimento com 3,24\% (Tabela 01), superou o município de Orizona entre os censos de 1991 e 2000.

O município de Orizona tem menor população, 14.300 pessoas em 2010, com somente 55\% de urbanização e menor taxa de crescimento geométrico populacional com 0,91\% em 2010 (Tabela 01).

Tabela 01. Dados diversos dos municípios - Abadiânia e Orizona. 1980-2010

\begin{tabular}{|c|c|c|c|c|}
\hline Dados & 1980 & 1991 & 2000 & 2010 \\
\hline \multicolumn{5}{|l|}{ Abadiânia } \\
\hline População Censitária & 9.030 & 9.402 & 11.452 & 15.757 \\
\hline Proporção de população urbana & 38,4 & 54,7 & 62,9 & 68,4 \\
\hline Taxa de crescimento Geométrico populacional (\%) & & 0,37 & 2,22 & 3,24 \\
\hline Densidade demográfica (hab/Km²) & & 9,00 & 10,97 & 12,81 \\
\hline \multicolumn{5}{|l|}{ Orizona } \\
\hline População Censitária & 12.362 & 12.471 & 13.067 & 14.300 \\
\hline Proporção de população urbana & 35,0 & 42,7 & 48,8 & 55,8 \\
\hline Taxa de crescimento Geométrico populacional (\%) & & 0,08 & 0,52 & 0,91 \\
\hline Densidade demográfica (hab/Km²) & & 6,32 & 6,62 & 7,25 \\
\hline
\end{tabular}

Fonte: Goiás, 2013.

\section{b.2 Alguns dados sociais}

Dos dados sociais apresentados na Tabela 02, têm-se números que corroboram com as informações já apresentadas, quando se tem disparidades contundentes entre os municípios. A começar pelo tema, saúde, o município de Orizona apresenta melhor condição de atendimento por oferecer um estabelecimento de saúde (SUS) para 1.021 habitantes, enquanto Abadiânia disponibiliza um para 1.432 habitantes.

Em relação à educação a proporção no número de alunos matriculados e a população, entre os municípios não apresenta grandes variações significativa de nota.

Na proporcionalidade de pessoas ocupadas, Orizonha tem a vantagem com 16,3\% e somente Abadânia com 11\%.

Quanto à quantidade de homens e mulheres residentes, nos municípios de Abadiânia e Orizona há mais homens que mulheres. Orizona tem grande vantagem no índice de alfabetizados, com aproximadamente 10 pontos percentuais a mais em relação à Abadiânia.

Orizona ainda apresenta melhores indicadores em relação à Abadiânia como no PIB per capita e no valor do rendimento médio tanto por domicilio quanto por trabalhador. 
Tabela 02. Sintese de informações sociais. Abadiânia e Orizona.

\begin{tabular}{l|r|r}
\hline \multirow{2}{*}{ Informações } & \multicolumn{2}{c}{ Municipios } \\
\cline { 2 - 3 } & \multicolumn{1}{c}{ Abadiânia } & \multicolumn{1}{c}{ Orizona } \\
\hline Estabelecimentos de Saúde SUS (Quantidade) & 11 & 14 \\
\hline Matrícula - Ensino fundamental - 2012 (Quantidade) & 2.176 & 1.854 \\
\hline Matrícula - Ensino médio - 2012 (Quantidade) & 716 & 477 \\
\hline Número de unidades locais (Quantidade) & 226 & 336 \\
\hline Pessoal ocupado total (Quantidade) & 1.796 & 2.325 \\
\hline PIB per capita a preços correntes (R\$) - 2011 & $7.460,31$ & $17.188,61$ \\
\hline População residente (Quantidade) - 2010 & 15.757 & 14.300 \\
\hline População residente - Homens (\%) & 51,3 & 51,7 \\
\hline População residente - Mulheres (\%) & 48,7 & 48,3 \\
\hline População residente alfabetizada (\%) & 83,3 & 94,0 \\
\hline $\begin{array}{l}\text { Valor do rendimento nominal médio mensal dos domicílios } \\
\text { particulares permanentes com rendimento domiciliar, por situação } \\
\text { do domicílio - Rural (R\$) }\end{array}$ & $1.562,99$ & $2.250,59$ \\
\hline $\begin{array}{l}\text { Valor do rendimento nominal médio mensal dos domicílios } \\
\text { particulares permanentes com rendimento domiciliar, por situação } \\
\text { do domicílio - Urbana (R\$) }\end{array}$ & $1.801,78$ & $1.977,60$ \\
\hline Índice de Desenvolvimento Humano Municipal - 2010 (IDHM 2010) & 0,689 & 0,715 \\
\hline Font & & \\
\hline
\end{tabular}

Fonte: IBGE, 2012

No município de Orizona o valor do rendimento médio mensal dos domicílios é maior na zona rural, situação inversa de Abadiânia, fato que se pode explicar pelo elevado número de pessoas na zona rural no município de Orizona, que atuam principalmente na produção de Cachaça.

Quanto ao Indice de Desenvolvimento Humano dos Municipios (IDHM), todos os municípios tem indicador inferior ao do estado de Goiás que foi de 0,735 no ano 2010. Abadiânia tem índice considerado médio e Orizona se classifica como alto.

Quando observado o rendimento médio do trabalhador (Tabela 03), tem-se que os dois municípios tem valores inferiores ao do Estado que foi de R\$ 2.039,90 em 2014.

Tabela 03. Rendimento Médio de Abadiânia, Orizona e Estado de Goiás (R\$)

\begin{tabular}{l|c|c|c|c}
\hline \multirow{2}{*}{ Localidade } & \multicolumn{4}{c}{ Periódos } \\
\cline { 2 - 5 } & $\mathbf{2 0 0 0}$ & $\mathbf{2 0 0 5}$ & $\mathbf{2 0 1 0}$ & \multicolumn{1}{c}{$\mathbf{2 0 1 4}$} \\
\hline ESTADO DE GOIÁS & 524,44 & 845,25 & $1.330,82$ & $2.039,90$ \\
Abadiânia & 268,82 & 579,48 & 768,50 & $1.236,69$ \\
Orizona & 291,57 & 581,31 & 883,79 & $1.328,31$ \\
\hline
\end{tabular}

Fonte: Goiás, 2015. 


\section{b.3 O Produto}

Em Abadiânia o setor econômico predominante na composição do Produto Interno Bruto PIB (em 2010) é o de serviços com 54,9\% (Tabela 04), seguido da agricultura com 27,4\%.

Dos municípios estudados Orizona é o que apresenta maior participação da agricultura na composição do PIB em 2010, com 44,3\% tendo em segundo lugar o setor de serviços com 36,8\% (Tabela 04).

Tabela 04. Produto Interno Bruto - 2010 (mil reais)

\begin{tabular}{l|r|r}
\hline \multicolumn{1}{c|}{ Descrição } & \multicolumn{1}{c|}{ Abadiânia } & \multicolumn{1}{c}{ Orizona } \\
\hline Valor Adicionado bruto da Agricultura & 30.074 & 105.213 \\
Valor Adicionado bruto da Indústria & 13.401 & 33.646 \\
Valor Adicionado bruto dos Serviços & 60.280 & 87.435 \\
Impostos sobre produtos líquidos de subsídios & 6.018 & 11.025 \\
PIB a preços correntes & 109.773 & 237.318 \\
\hline
\end{tabular}

Fonte: IBGE, 2014.

Nenhum dos municípios tem a indústria com grande destaque na composição do PIB. Fato que mostra que os DIs ali instalados, não foram capazes de atrair empresas que fizessem deste setor destaque local ou regional.

Observando a participação do PIB dos municípios em relação ao PIB do Estado de Goiás, tem-se ligeira queda de Orizona e evolução de Abadiânia, no caso desta ultima cidade se pode creditar ao crescimento do setor de comercio com o advento da maior utilização do Lago de Corumbá IV (Gráfico 01).

Gráfico 01. Participação do PIB a preços correntes de Abadiânia e Orizona em relação ao PIB do Estado de Goiás

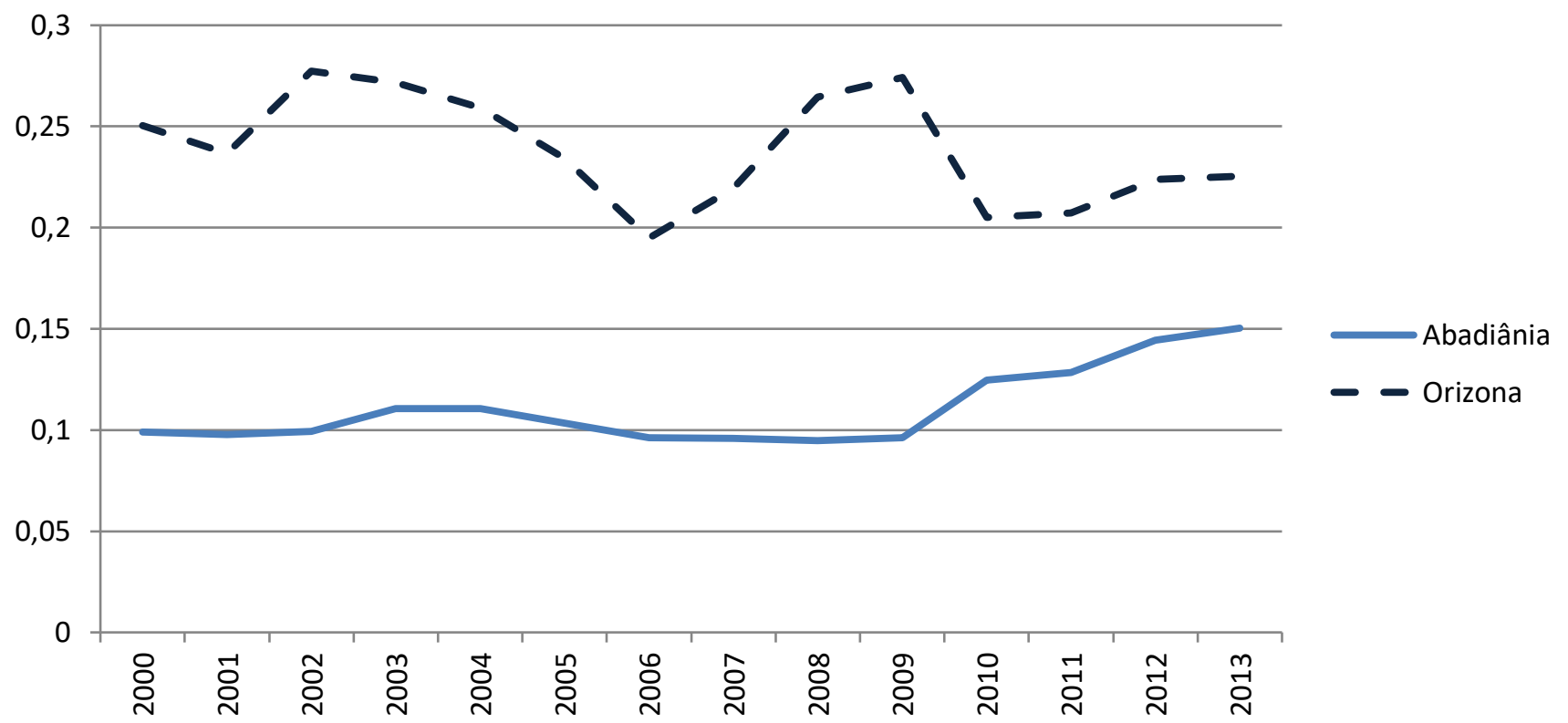

Fonte: Goiás, 2015. 
Quando se compara os dados dos setores segundo a formação do Valor Adicionado Bruto dos dois municípios em relação aos do estado de Goiás (Gráfico 02), tem-se que:

- o setor agropecuário dos dois municípios tem participação irrelevante perante o do Estado, com crescimento pequeno de Abadiânia;

- o setor industrial do município teve substancial queda de sua já pequena participação e recuperação parcial a partir de 2010. E relativa manutenção da situação de Abadiânia em relação ao Estado. E se pode acrescentar que no caso de Orizona a melhora ocorrida foi motivada pela melhor colocação da cachaça do município no mercado brasileiro;

- o setor de serviço se destacou em Abadiânia em virtude do maior emprego para lazer do lago do Corumbá IV, que intensificou novas construções e visitações nos fins de semana e feriados;

- no setor da Administração Pública, nos dois municípios, há uma tendência de convergência entre os dois após 2010.

Grafíco 02. Participação do Valor Adicionado Bruto a preços básicos da Agropecuária, da Indústria, do Serviço e da Administração Pública de Abadiânia e Orizona em relação ao de Goiás.
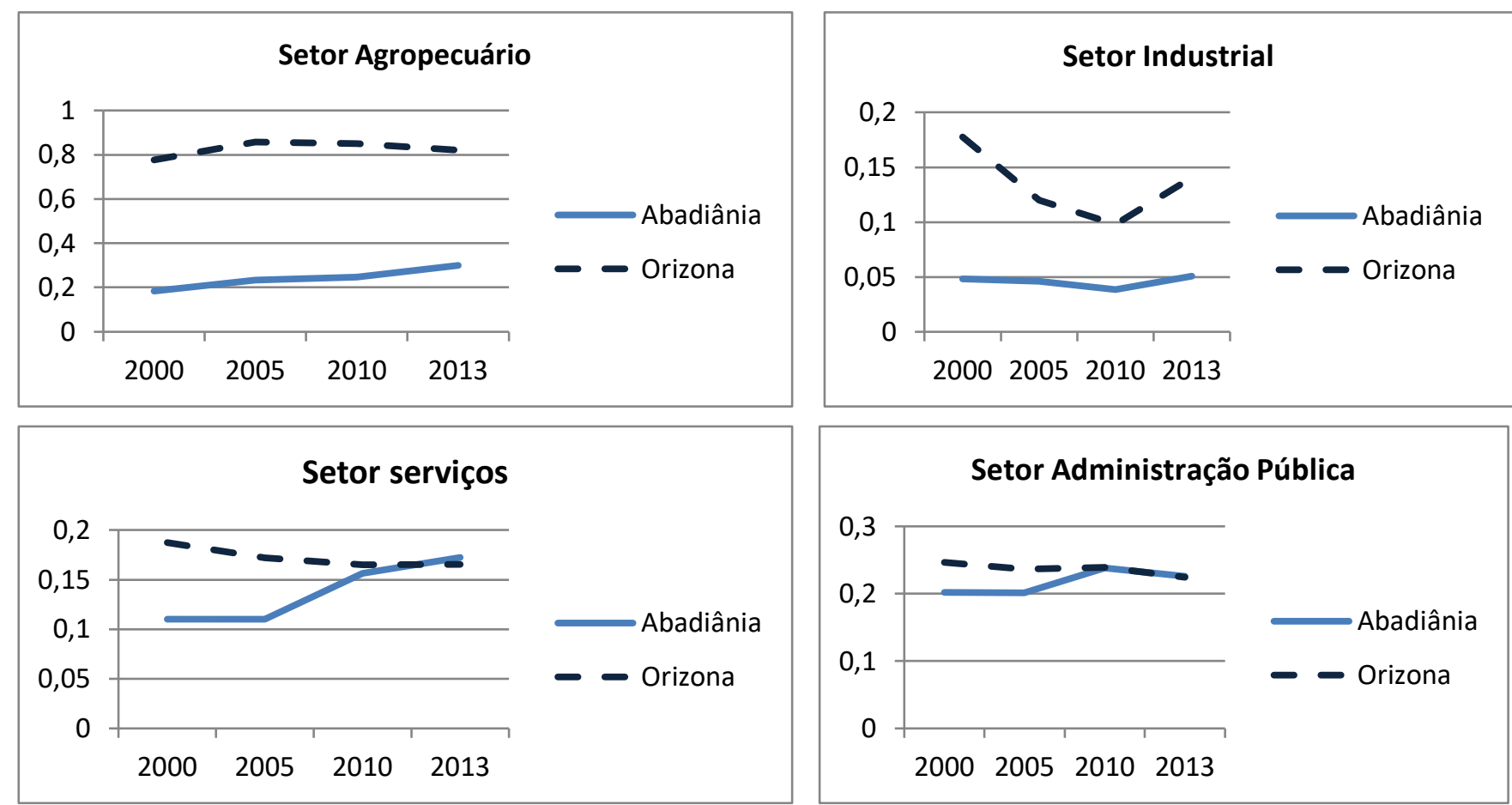

Fonte: Goiás, 2015.

\section{OS REFLEXOS DOS DISTRITOS NOS MUNICÍPIOS DE ABADIÂNIA E ORIZONA}

Os dados abaixo apresentados são resultados da aplicação dos questionários às empresas instaladas nos DIs existentes nos municípios focos da pesquisa.

Quando comparado o número de empresas instaladas nos DIs dos dois municípios estudados (Abadiânia e Orizona), tem-se que este quantitativo é inexpressivo em relação ao total existente dentro de ambos os municípios. Em Abadiânia, tem-se entre formais e informais, mais de 20 indústrias de produtos tradicionais (principalmente alimentares e construção civil) e em Orizona, há mais de 100 fabricas de 
bebidas - cachaça, por exemplo. Segundo informações (informais) das prefeituras dos municípios.

Os ramos de atividade das empresas instaladas nos Distritos Industriais dos dois municípios são variados, tendo indústrias alimentares, madeiras, metálicas, rações/adubos, produtos para construção civil e vestuário.

Das empresas, somente uma é considerada pequena empresa (com receita operacional bruta anual entre $\mathrm{R}$ \$ 2,4 milhoes e R\$ 16 milhões) as demais são microempresas (com receita operacional abaixo de 2,4 milhões). E os recursos para formação do capital social, originados no município, somam $43,3 \%$.

Do pessoal envolvido nas empresas, 46,7\% dos diretores moram em outros municípios no qual a empresa está instalada. As pessoas em cargos de gerente, pessoal administrativo e operacional, 100\% moram na cidade em que a empresa está instalada.

O grau de instrução do pessoal das empresas pesquisas ainda é baixo, do total, considerando diretores, gerentes, pessoal administrativo e operacional, há 5,6\% com ensino fundamental completo, $26,1 \%$ com ensino médio incompleto, 35,6\% com ensino médio completo, 16,1\% com ensino superior incompleto e 14,4\% com ensino superior completo, sendo que os diretores tem maior escolarização.

Em relação ao grau de especialização da mão de obra, tem-se que $29 \%$ são considerados especializados, 46,1\% são semi-especializados e $25 \%$ não tem especialização. Tal condição se reflete no valor da remuneração recebida, sendo 66,7\% com remuneração com até dois salários mínimos, 22,2\% recebem entre três e quatro salários mínimos e 11,1\% com remuneração acima de quatro salários mínimos.

A atuação das empresas como demandantes de matéria-prima local é muito baixa, correspondendo a 3,4\%, valor que sobe para 38\% em relação ao mercado regional, enquanto, $51,7 \%$ dos produtos vêm de fora do estado e 6,7\% do exterior. Quanto à destinação dos bens produzidos, 94,5\% vai para o mercado goiano e 5,6\% para fora do estado (Tabela 05).

Tabela 05. Origem da matéria prima e destino do produto final

\begin{tabular}{l|r|r}
\hline \multicolumn{1}{c|}{ Descrição } & $\begin{array}{c}\text { Origem da } \\
\text { Materia-Prima }\end{array}$ & $\begin{array}{c}\text { Destino do } \\
\text { Produto final }\end{array}$ \\
\hline Município & 3,4 & - \\
Regional até 100 km (do município) & 17,9 & 36,7 \\
No Estado (acima de 100 km do municipio) & 20,2 & 57,8 \\
Fora do Estado (no Brasil) & 51,7 & 5,6 \\
Exterior & 6,7 & - \\
\hline
\end{tabular}

Fonte: da pesquisa

Quando visto os benefícios que as empresas recebem do Estado além das condições oferecidas nos Distritos, no momento da pesquisa somente há uma com incentivo fiscal do governo do estado e três com financiamento público. Há que se observar que várias destas empresas já usufruíram dos incentivos fiscais e de financiamento público, mas que no momento tais benefícios se encontram com os contratos finalizados. Em contrapartida, é dado aos funcionários, seguro saúde e/ou plano de saúde e seguro de vida (quatro empresas). E a atuação destas empresas nos municípios acontece com campanhas sobre meio ambiente (duas empresas) e incentivo ao primeiro emprego (cinco empresas).

Quanto aos serviços terceirizados a relação das empresas com o local é mais efetiva, pois a distância de outros municípios vizinhos torna muito dispendioso trazer serviços como de segurança, manutenção e de contabilidade, neste caso pelo próprio tamanho dos estabelecimentos (Tabela 06). 
Tabela 06. Origem dos serviços terceirizados (em percentual - \%)

\begin{tabular}{lrr}
\hline \multicolumn{1}{c|}{ Serviços } & Do Município & \multicolumn{1}{c}{ No Estado } \\
\hline Manutenção em geral & 51,1 & 48,9 \\
Contabilidade & 66,7 & 33,3 \\
Advogado & 33,3 & 66,7 \\
Segurança & 100,0 & 0 \\
Informática & 33,3 & 66,7 \\
Transporte & 53,3 & 46,7 \\
\hline
\end{tabular}

Fonte: da pesquisa

Pelos dados expostos se percebe que os municípios se beneficiaram pouco com as empresas instaladas nos Distritos Industriais de responsabilidade do governo estadual, tem-se que o lado positivo destes espaços é a oferta de empregos. Em fim, estes espaços ainda não cumprem a relação preconizada pelos teóricos estudados e ainda não conseguiram fazer do local o polo de desenvolvimento esperado.

\section{CONCLUSÃO}

Diante dos resultados apurados, pode-se observar que a presença do Estado fomentando a industrialização através de distritos industriais em pequenos municípios, nestes casos estudados, não criou atmosfera de atração de outros empreendimentos para o encadeamento para frente ou para trás como coloca Hirschman, ou seja, não se tem a força de uma empresa motriz conforme pensamento de Perroux.

O grau de instrução das pessoas que atuam nas empresas, que ainda é baixo, com 5,6\% com ensino fundamental completo e $25,1 \%$ com ensino médio incompleto $14,4 \%$ com superior completo, fato que ajuda a entender o baixo nível salarial, com somente $11,1 \%$ recebendo acima de quatro salários minímos.

Por outro lado, as empresas dos DIs além do pequeno número, tem pequena relação com o mercado, tanto demandante quanto ofertante com os municípios em que estão instaladas, com aquisição de apenas 3,4\% da matéria prima local, fugindo ao propósito dos distritos industriais, que é o de promover o crescimento e desenvolvimento local. E são poucas ações que desenvolvem em relação à sociedade dos municípios em que estão instaladas no local.

Tem-se, portanto, que os recursos empregados pelo Estado com implementação de espaços destinados a instalações de empresas que não tem cumprido seu objetivo de fomentar a economia local. Para tanto, há que se repensar a política industrial empregando espaços para indústrias em pequenos municipios, com envolvimento maior da população local, incentivando realmente as capacidades locais, observando que nestes em pequenos municípios o tratamento diferenciado às pequenas empresas, desburocratizando a aquisição dos terrenos, poderá reduzir desperdícios de recursos públicos, com vários espaços (estadual e municipal) com o mesmo objetivo, e subutilizado.

\section{REFERÊNCIAS}

BARRETO, Sônia Regina de Jesus. Uma análise dos impactos ambientais em distrito industrial: o 
caso do Porto Seco no município de Anápolis-GO. 2009. 73 f. Trabalho acadêmico (Graduação) - Curso de Geografia. Unidade Universitária de Ciências Sócio-Econômicas e Humanas da UEG. 2009.

BECATTINI, Giacomo. Industrial districts: a new approach to industrial change. Northampton (Massachusctts): Edward Elgar, 2004.

CANO, Wilson. Desconcentração produtiva regional do Brasil 1970 - 2005. São Paulo: Editora UNESP, 2008.

CASTRO, Antonio Barros. A rica fauna da política industrial e a sua nova fronteira. Revista Brasileira de Inovação, v. 01, n. 02, jul/dez, 2002, p. 253-274.

CASTRO. Joana D’arc Bardella. Anápolis: desenvolvimento industrial e meio ambiente. Anápolis: Associação Educativa Evangelica, 2004. P. 152.

CHANG, Ha-Joon.The Political Economy of Industrial Policy. London: MacMillan Press, 1994.

CUNHA, Wânia Chagas Faria. Contexto socioeconômico de Goiás na década de 1970 e a adoção da política de industrialização via distritos industriais. Boletim Goiano de Geografia. Goiânia, v. 30, n. 1, p. 69-92, jan./jun. 2010

FERRAZ, João Carlos; PAULA, Germano Mendes; KUPFER, David. Política industrial. In: KUPFER, David; HASENCLEVER, Lia. Economia industrial: fundamentos teóricos e práticos no Brasil. Rio de Janeiro: Campus, 2002. p. 545-567. (Capítulo 23)

FERREIRA, Mario C. P. J.. Distritos industriais: opção de desenvolvimento. 2003. 146 f. Dissertação (Mestrado Profissional em Engenharia Mecânica) - Faculdade de Engenharia Mecânica.Universidade Estadual de Campinas. Campinas. 2003.

FLEURY, Maria Tereza Leme; FLEURY, Afonso (Org.). Política Industrial - I. São Paulo: Publifolha, 2004. (Coleção Biblioteca Valor).

FUJITA, Masahisa; KRUGMAN, Paul. The new economic geography: Past, present and the future. Papers Regional Science, n. 83, p. 139-164, 2004. Disponível em: http://ideas.repec.org/a/spr/ecogov/v83y2003i1p139-164.html. Acesso em: 15/01/2012.

GIL, Antonio Carlos. Como elaborar projetos de pesquisa. 5. ed. São Paulo: Atlas, 2010.

GOIÁS. Assembleia Legislativa. Projeto de lei n. 84-G. Autoriza o Poder Executivo a organização uma Sociedade de Ações, sob a denominação de Companhia de Distritos Industriais de Goiás (Goiásindustrial) e da outras providencias. Goiânia, 1973. p. 03. (mimeo).

GOIÁS. Invista em Goiás. Disponível em: http://www.goias.gov.br/paginas/invista-em-goias. Acesso em: 28/03/2012.

GOIÁS. Instituto Mauro Borges. Banco de dados estatístico do Estado de Goiás - dados selecionados. Goiânia: IMB, 2015.

GOIÁS. Lei $\mathbf{n}^{\mathbf{0}}$ 7.766, de 20 de novembro de 1973. Autoriza o Poder Executivo a organizar uma Sociedade por Ações, sob a denominação de Companhia de Distritos Industriais de Goiás (GOIÁSINDUSTRIAL) e dá outras providências. Goiânia, 1973a. (D.O. de 07-12-1973)

GOIÁS. Secretaria de Estado de Gestão e Planejamento. Estatísticas Básicas Trimestrais - 2013. Goiânia: Secretaria de Gestão e Planejamento do Estado de Goiás, 2013.

GOIÁS. Secretaria do Planejamento e Desenvolvimento (Seplan). Economia e desenvolvimento. 
Conjuntura socioeconômica de Goiás. Goiânia: Seplan, 1999, ano I, n. 1, out/dez. 1999.

GOIÁS. Secretaria do Planejamento e Desenvolvimento (Seplan). Economia e desenvolvimento. Conjuntura socioeconômica de Goiás. Goiânia: SEPLAN, 2000, ano I, n. 2, jan/mar. 2000.

GOIÁS. Secretaria do Planejamento e Desenvolvimento (Seplan). Perfil competitivo das regiões de planejamento do Estado de Goiás. Goiânia: Seplan, 2007

GOIÁS. Secretaria de Estado de Gestão e Planejamento. Goiás em Dados 2011. Goiânia: SEGPLAN, 2011.

GOIÁS. Secretaria do Planejamento e Desenvolvimento (Seplan). Indicadores econômicos: séries estatísticas básicas. Goiânia: SEPLAN, 2002.

GOIAINDUSTRIAL. Nossa atuação. Disponivel em:

http://www.goiasindustrial.com.br/w4/index.php/nossa-atuacao\#tudo. Acesso em: 10/12/2014.

HEIDEMANN, Francisco; SALM, José Francisco (Org). Políticas públicas e desenvolvimento: bases epistemológicas e modelos de análise. Brasilia: Editora Universidade de Brasilia, 2009.

HIRSCHMAN, Albert O. Estratégia do desenvolvimento econômico. Rio de Janeiro: Fundo de Cultura, 1961.

INSTITUTO BRASILEIRO DE GEOGRAFIA E ESTATÍSTICA (IBGE). Contas Nacionais do Brasil. Rio de Janeiro: IBGE, 2012. Disponível em:

http://www.ibge.gov.br/home/estatistica/economia/contasnacionais. Acesso em: 03/11/2012.

INSTITUTO BRASILEIRO DE GEOGRAFIA E ESTATÍSTICA (IBGE). IBGE Cidades. Rio de Janeiro: IBGE, 2014. Disponível em:

http://www.cidades.ibge.gov.br/xtras/perfil.php?lang=\&codmun=520010\&search=goias. Acesso em: 10/08/2014.

LAURIA, Ivna Olimpio; MOISÉS, Aristides; PASQUALETTO, Antonio. Distritos empresariais como agentes de desenvolvimento regional em áreas públicas em Aparecida de Goiânia-GO. Estudos, Goiânia, v. 39, n.1, p. 61-79, jan/mar. 2012.

MARSHALL, Alfred. Principio de economia: tratado introdutório. São Paulo: Nova Cultura, 1996. (Vol. 1. Coleção Os economistas)

MYRDAL, Gunnar. Teoria econômica e regiões subdesenvolvidas. 3. ed. Rio de Janeiro: Saga, 1972.

PERROUX, François. A economia do Século XX. Lisboa: Morais Editora, 1967.

RAMPAZZO, Lino. Metodologia científica. 5. ed. São Paulo: Edições Loyola, 2010.

RIBEIRO, Iraciara A. Roque de Araújo. O distrito agroindustrial de Anápolis - DAIA: mercado de trabalho e formação profissional. 2008. 145 f. Dissertação (Mestrado em Geografia) - Instituto de Estudos Sócio-Ambientais da Universidade Federal de Goiás. Goiânia, 2008.

SABOIA, JOÃO. Desconcentração industrial no Brasil nos anos 90: um enfoque regional. Pesquisa e Planejamento Econômico, Rio de Janeiro, v. 30, n. 1, p. 69-116, abr. 2000.

SILVA, Rodrigo Mendes. O distrito agroindustrial de Anápolis e as mudanças na base econômica do estado de Goiás. IV Encuentro Internacional Económia Política y Derechos Humanos. Universidad Popular Madres de Plaza de Mayo. Centro de Estudos Económicos y Monitoreo de las Politicas Públicas.

6 de abril de 2000. 
SILVA, Rodrigo Mendes; MENDONÇA, Marcelo Rodrigues. DAIA: mitos e discursos sobre emprego e empregabilidade. Espaço em Revista, v. 12, n. 02, jul/dez 2010. p. 42 - 65.

STORPER, Michael. The regional world: territorial development in a global economy. New York: The Guilford Press, 1997.

SUZIGAN, Wilson; FURTADO, João. Política Industrial e Desenvolvimento. Revista de Economia Política, vol. 26, nº 2 (102), pp. 163-185 abril-junho/2006. 